\title{
ANALISIS SOSIAL HUKUM ISLAM DALAM QS AN-NUR AYAT 22
}

\author{
Oleh : Mayyadah ${ }^{1}$ \\ 1E-mail:mayyadah@iainpalu.ac.id \\ Fakultas Syariah IAIN Palu
}

\begin{abstract}
Abstrak
Tulisan ini mencoba untuk mengkaji teks dan konteks dari QS An-Nur ayat 22. Secara historis, teks ayat 22 dari QS An-Nur turun berkaitan dengan terjadinya peristiwa hadīs al-ifki yang menimpa 'Aisyah radiyallahu 'anha. Peristiwa tersebut diprediksi oleh para sejarawan terjadi setelah perang Bani Musthaliq pada tahun 5 atau $6 \mathrm{H}$. Beberapa aspek sosial hukum Islam yang terkandung dalam ayat ini adalah prinsip-prinsip etika dalam interaksi sosial, sikap individu dalam menghadapi fitnah atau hoaks, dan konsekuensi hukum yang ditetapkan oleh syariat terhadap pelaku dan penyebar fitnah.
\end{abstract}

Kata Kunci: Asbāb Nuzūl; Konteks Historis; Sosial Hukum; Hoaks.

\begin{abstract}
This paper aims to analyze QS An-Nur verse 22, from text to context. Historically, the text of verse 22 of QS An-Nur came down related to the occurrence of the hadis al-ifki, incident that hit 'Aisyah radiyallahu 'anha. That event predicted by historians took place after the Bani Musthaliq war around 5 or $6 \mathrm{H}$. Some of the social aspects of Islamic law which contained in this text are ethical principles in social interaction, individual attitudes in dealing with slander or hoaxes, and the legal consequences stipulated by the Shari'a against perpetrators and spreaders of fake news or hoaxes.
\end{abstract}

Keywords: Asbāb Nuzūl; historical context; social law; hoax.

\section{PENDAHULUAN}

Al-Qur'an yang turun secara gradual dalam rentang waktu yang lama menunjukkan adanya interaksi nas dengan konteks sosial yang terjadi pada masyarakat Arab ketika itu. Nas al-Qur'an bukan hanya mereformasi tatanan masyarakat, tetapi juga merevolusi konsep-konsep formal menjadi konsep-konsep baru yang lebih mencerahkan. ${ }^{1}$ Untuk memahami konsep yang ditetapkan ayat-ayat al-Qur'an secara utuh, maka penelusuran terhadap asbāb nuzūl (sebab-sebab turunnya ayat) merupakan salah satu pendekatan dalam mengkaji aspek historis sosial hukum ayat tersebut.

Secara garis besar, surah an-Nur dikategorikan sebagai surah madaniyyah yang

${ }^{1}$ Irma Riyani, "Menelusuri Latar Historis Turunnya al-Qur'an dan Proses Pembentukan Tatanan Masyarakat Islam", Al-Bayan vol. 1 No. 1 (Juni 2016), h. 28. 
mayoritas berisi hukum-hukum keluarga dan mencakup hukum sosial kemasyarakatan. Di antara ayat-ayat dalam surah an-Nur adalah pembahasan tentang adab-adab dalam masyarakat seperti aturan bertamu, hukum jilbab, kewajiban mengendalikan pandangan ke lawan jenis, larangan $i k h t i l a>t\}$, dan hukum-hukum yang menyangkut hubungan suami istri. Selain itu, surah an-Nur juga banyak menerangkan tentang penetapan sanksi ( $h\} a d$ ) meliputi $h$ \}ad bagi pezina, $h\} a d$ bagi yang menuduh orang lain berzina dan aturan hukum $l i^{\prime} a>n .^{2}$

Adapun ayat 22 surah an-Nur menjelaskan tentang beberapa prinsip nilai dan kaidah hukum bagi individu dalam berinteraksi sosial yang berkaitan erat dengan peristiwa yang melatarbelakangi turunnya ayat ini. Beberapa masalah yang akan dikaji lebih lanjut dalam tulisan ini adalah peristiwa apa yang menjadi latar belakang penetapan hukum pada ayat 22 surah an-Nur dan bagaimana aspek historis yang terdapat dalam ayat 22 surah an-Nur? Dari segi konteksnya, tulisan ini juga menganalisis aspek sosial hukum Islam yang terdapat dalam ayat tersebut.

\section{METODE PENELITIAN}

Jenis penelitian ini tergolong kualitatif dengan menggunakan pendekatan penelitian pustaka (Library Research), yakni suatu peneltian dengan cara menuliskan, mengklarifikasi dan menjadikan data yang diperoleh dari berbagai sumber tertulis. Adapun metode pengumpulan data yakni mengguakan tehnik dokumen (studi pustaka), mengutip dan menganalisis data dengan tehnik dokumen dimaksudkan untuk mengumpulkan data terkait yang dimuat dalam dokumen-dokumen berupa buku-buku, jurnal dan hasil penelitian berupa skripsi, tesis, dan disertasi.

\section{HASIL \& PEMBAHASAN}

\section{A. Latar Belakang Turunnya Qs An-Nur Ayat 22}

Ayat 22 dalam surah An-Nur memiliki kaitan erat dengan gambaran peristiwa yang dijelaskan Al-Qur'an dalam sepuluh ayat sebelumnya yaitu ayat 10 sampai dengan ayat 21. Peristiwa tersebut dikenal dalam sejarah Islam sebagai hadis| al-ifki (berita dusta) yang menimpa istri Rasulullah saw. Aisyah. Dalam riwayat dikisahkan bahwa ketika Aisyah tertinggal dari rombongan Rasulullah dalam sebuah perjalanan sehingga ia terpaksa pulang bersama seorang Sahabat bernama Shafwan bin Ma'tal yang kebetulan menemukannya di tengah jalan, maka berhembuslah isu tentang perselingkuhan Aisyah dengan Shafwan. Kejadian ini bukan hanya menyebabkan konflik psikologis antara Aisyah dengan Rasulullah, tetapi juga menjadi polemik di antara Sahabat-Sahabat Rasulullah termasuk Abu Bakar as-Siddiq dalam masa yang

2 Muhłammad 'Ali al-Sabuni, Rawa>'i al-Baya>n Tafsi>r A<<ya>t al-Ah\}ka>m min al-Qur'a>n, Juz 2 (Cet. I; Jakarta: Dar al-Kutub al-Islamiyyah 2001), h. 3. 
cukup lama. ${ }^{3}$

Setelah Allah menurunkan sepuluh ayat yang berisi pembebasan dan kesucian diri Aisyah dari segala tuduhan tersebut, maka Abu Bakar pun menjadi geram terhadap salah satu kerabatnya yang juga ikut menyebarkan berita dusta sebagaimana yang diceritakan dalam riwayat berikut:

روى ابن جرير الطبري عم عائشة رضي الله عنها قالت: لما نزل قوله تهاله فالى: (إن الذين جاءوا

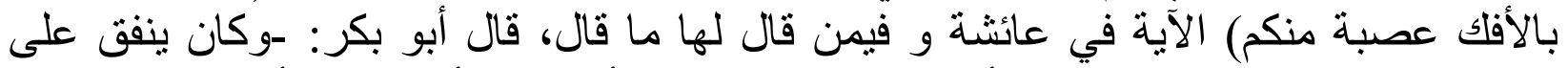

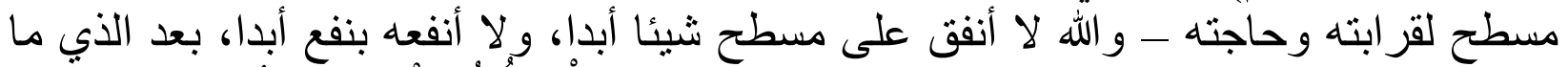

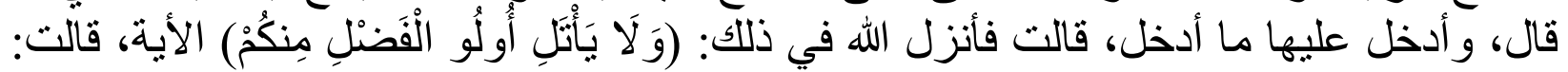

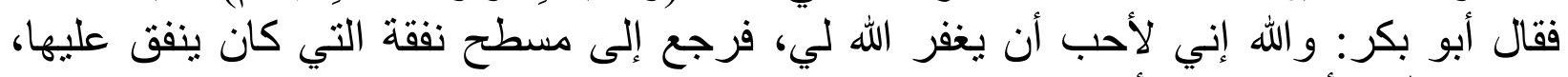
وقال: و الله لا أنز عها منّه أبدا. Dari Jarir al-Thabari dari 'Aisyah radjiyallah 'anha> bahwasanya ia berkata: ketika turun firman Allah innallaz $\mid i>n a$ ja>'u> bi al-ifki 'us\}batun minkum hingga akhir ayat tentang Aisyah dan orang-orang yang telah menuduhnya, maka Abu Bakar yang selama ini menanggung nafkah Misthah karena hubungan kekerabatan dan karena kebutuhan hidup (Misthah) pun berkata: Demi Allah, saya tidak akan mau lagi untuk menafkahi Misthah karena apa yang telah ia tuduhkan dan perbuat kepada Aisyah! Aisyah pun berkata: maka Allah lalu menurunkan ayat wa la> ya'tali ulu> al-Fad\}l minkum hingga akhir ayat. Berkatalah Abu Bakar: Demi Allah, saya lebih menyukai jika Allah mengampuniku. Lalu ia pun kembali menafkahi Misthah sebagaimana yang ia lakukan selama ini. Dan Abu Bakar berkata: Demi Allah, saya tidak akan lagi menghentikan nafkahku atas Mistjah selama-lamanya.

Dari riwayat tersebut, dapat disimpulkan bahwa sikap Abu Bakar yang bersumpah tidak akan menafkahi lagi salah satu kerabatnya itu menjadi latar belakang atau sabab $n u z \bar{u} l$ ayat 22 dari surah An-Nur berikut:

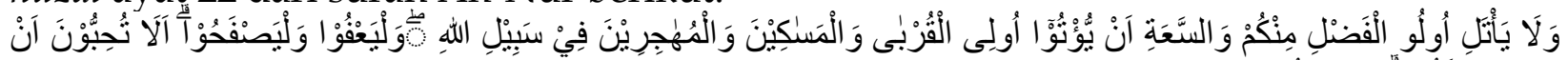

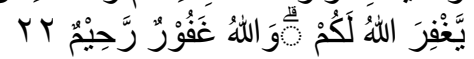

Terjemahnya:

Dan janganlah orang-orang yang mempunyai kelebihan dan kelapangan di antara kamu bersumpah bahwa mereka (tidak) akan memberi (bantuan) kepada kerabatnya, orang-orang miskin, dan orang-orang yang berhijrah di jalan Allah, dan hendaklah mereka memaafkan dan berlapang dada. Apakah kamu tidak suka bahwa Allah mengampunimu? Dan Allah Maha Pengampun, Maha Penyayang. ${ }^{5}$

3 Peristiwa hadi>s| al-ifki ini dapat disimak secara rinci dalam riwayat Bukhari Muslim yang bersumber dari penuturan Aisyah. Lihat Jalaluddin al-Suyuti, Asba>b al-Nuzu>l (Cet. I; Bairu>t: Mu'assah al-Kutub al-Saqafiyyah, 2002), h. 183.

4 Muhammad Ali As-Shabuni, Rawa'i al-Baya>n Tafsi>r A<ya>t al-Ah\}ka>m min al-Qur'a>n, Juz 2, h. 83.

${ }^{5}$ Kementrian Agama RI, Terjemah QS An-Nur ayat 22 dalam Qur'an Kemenag Versi 1.3.3.9 (Aplikasi Mobile Android), Lajnah Pentashihan Mushaf Al-Qur'an, 2018. 
Adapun penafsiran dari ayat ini adalah bahwa berbuat baik terhadap seseorang itu hendaklah senantiasa dilakukan meski orang tersebut membalasnya dengan keburukan. Oleh karena itu, Allah memerintahkan agar orang-orang yang diberikan kemuliaan oleh Allah dari segi agama dan kemampuan dari segi ekonomi untuk tidak memutuskan tali silaturahmi terhadap kerabatnya. Termasuk juga kepada orang-orang yang tergolong tidak mampu, orang-orang miskin, dan kaum muhajirin. Allah memperingatkan manusia untuk tetap menyantuni mereka meskipun mereka berbuat jahat. Hendaklah kejahatan mereka dimaafkan sebagaimana Allah yang Maha Pemaaf dan Penyayang kepada hamba-hambaNya. ${ }^{6}$

\section{B. Aspek Historis Qs An-Nur Ayat 22}

Secara kronologis, ayat 22 dari surah an-Nur turun pada saat Rasulullah telah hijrah ke Madinah. Fakta sejarah ini dapat dibuktikan berdasarkan riwayat dari Aisyah yang menceritakan tentang peristiwa $h\} a d i>s \mid$ al-ifki. Dalam riwayat Aisyah tersebut diketahui bahwa sabab nuzu>l ayat 22 surah An-Nur turun setelah Allah membersihkan tuduhan orang-orang munafik kepada Aisyah dengan turunnya ayat 11-20 dari surah An-Nur. Dari riwayat Aisyah itu pula diketahui bahwa hadi $>s \mid$ al-ifki atau berita dusta tentang dirinya muncul setelah kembalinya kaum muslim dari sebuah perang bersama Rasulullah. Para ulama menyebutkan bahwa perang yang dimaksud adalah perang Bani Mushthaliq. ${ }^{7}$

Berdasarkan catatan sejarah Islam, perang Bani Mushthaliq diprediksi terjadi pada bulan Sya'ban tahun ke 5 atau ke 6 setelah hijrah. ${ }^{8}$ Dengan demikian, jika sabab nuzu>l ayat 22 turun setelah peristiwa fitnah kepada Aisyah, sementara fitnah tersebut terjadi setelah perang Bani Mushthaliq, maka peristiwa Abu Bakar yang menjadi latar turunnya ayat 22 surah An-Nur juga terjadi pada tahun yang sama dengan terjadinya perang tersebut yaitu sekitar tahun ke 5 atau 6 Hijriyah.

Dalam sabab nuzul ini muncul pula nama salah satu kerabat Abu Bakar yang ikut terpengaruh oleh berita fitnah perselingkuhan Aisyah yaitu Misthah. Siapakah Misthah? Misthah adalah termasuk ke dalam golongan Sahabat. Dia bernama lengkap 'Auf bin Usasah bin al-Mutthalib bin 'Abdil Manaf bin Qusay merupakan sepupu dari Abu Bakar. Ia ikut dalam beberapa peperangan bersama Rasulullah di antaranya Perang Badar dan Perang Khaibar. Ibu Misthah bernama Salma bint Abi Ruhm yang tak lain merupakan bibi Abu Bakar. Misthah dan ibu kandungnya termasuk orang yang

\footnotetext{
6 Shalih bin 'Abdul 'Aziz al Syaikh al-Tafsi>r al-Muyassar (Madi>nah: Maktabah al-Malik al-Fahd, $1420 \mathrm{H})$, h. 352.

7 Ibnu H\}ajar al-'Asqalani, Fath\} al-Ba>ri> bi Syarh al-Bukha>ri>, Juz 10, Hadis Nomor 4750 (Cet. I; Riyad: Dar Taibah, 2005), h. 381.

8 Perkiraan terjadinya perang tersebut pada tahun ke 6 Hijriyah dikemukakan oleh Ibnu Hisya $>$ m. Lihat 'Umar 'Abdussalam al Tadmuri (ed.), al-Sirah al-Nabawiyyah li Ibni Hisya>m, Juz 3 (Bairu>t: Dar al-Kitab al-'Arabiy 1990), h. 235. Sementara Ibnu Hajar memprediksinya pada tahun ke 5 Hijriyah. Lihat Ibnu H\}ajar al-'Asqalani, Fath\} al-Ba>ri> bi Syarh al-Bukha>ri>, Juz 10, h. 404.
} 
berhijrah ke Madinah (Muhajirin). Misthah adalah anak yatim sejak ia masih belia, sementara ibunya tidak mampu membiayai kehidupan mereka. Oleh sebab itu, Abu Bakar pun ikut membantu perekonomian mereka di samping karena hubungan kekerabatan mereka yang sangat dekat. ${ }^{9}$

Saat isu perselingkuhan Aisyah tersebar, Ibu Misthah lebih memilih membela Aisyah meski tuduhan itu juga dilontarkan oleh putranya sendiri. Awalnya Aisyah sama sekali tidak mengetahui bahwa salah satu keluarganya juga ikut menuduhnya berselingkuh. Namun dalam riwayat disebutkan bahwa ketika Aisyah meminta Ummi Misthah menemaninya ke suatu tempat untuk menunaikan hajat, tiba-tiba Ummi Misthah tergelincir oleh pakaiannya dan latah berseru: Celakalah Misthah! yang diucapkannya berulang kali. Aisyah yang heran mendengar ucapan wanita itu pun bertanya mengapa seorang ibu menghardik putra kandungnya sendir, padahal putranya adalah salah satu Sahabat Rasulullah yang ikut perang Badar. Akhirnya Ummu Misthah pun menceritakan tentang apa yang diucapkan dan diperbuat oleh anaknya bersama orang-orang penyebar fitnah itu. ${ }^{10}$

Tatkala ayat 11 surah An-Nur turun yang membuktikan bahwa salah satu penyebar dusta itu adalah orang-orang terdekat, maka tak heran jika Abu Bakar menjadi geram dan marah. Hati Abu Bakar terluka setelah mengetahui bahwa di antara yang menuduh putrinya berselingkuh justru dari keluarganya sendiri, orang dekat yang selama ini ia nafkahi dan sayangi. Sebagaimana Allah berfirman dalam Surah An-Nur ayat 11 sebagai berikut:

Terjemahannya:

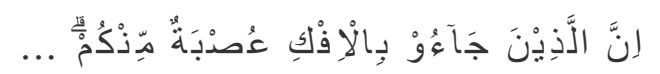

Sesungguhnya orang-orang yang membawa berita itu bohong itu adalah dari golongan kamu (juga)...11

Abu Bakar yang juga seorang manusia biasa itu pun lantas bersumpah tidak akan lagi membantu biaya hidup sepupunya tersebut sebagai hukuman atas apa yang telah diperbuatnya terhadap putrinya. Namun rupanya perilaku Abu Bakar tersebut tidak diridhai oleh Allah sehingga turunlah ayat 22 surah An-Nur yang meminta Abu Bakar untuk memaafkan kerabatnya.

Jika pada surah An-Nur ayat 22 Allah menganjurkan manusia untuk memaafkan saudaranya, maka pada ayat selanjutnya Allah juga memberikan ketegasan bagi para tukang fitnah yang tidak mengakui kesalahannya dan enggan bertaubat. Hal ini tercantum pada QS An-Nur ayat 23-24:

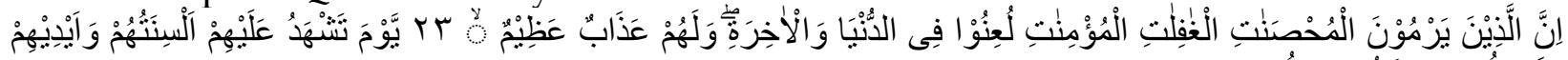

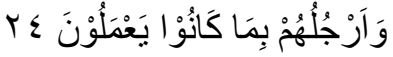

\footnotetext{
9 Ibnu H\}ajar al-'Asqalani, Fath\} al-Ba>ri> bi Syarh al-Bukha>ri>, Juz 10, Hadis Nomor 4750, h. 408.

${ }^{10}$ Muhłammad 'Ali al-Sabuni, Rawa'i al-Baya>n Tafsi>r A<ya>t al-Ah\}ka>m min al-Qur'a>n, Juz 2, h. 96.

${ }^{11}$ Kementrian Agama RI, Terjemah QS An-Nur ayat 11 dalam Qur'an Kemenag Versi 1.3.3.9 (Aplikasi Mobile Android), Lajnah Pentashihan Mushaf Al-Qur'an, 2018.
} 
Terjemahannya:

Dan sesungguhnya orang-orang yang menuduh perempuan-perempuan baik, yang lengah dan beriman (dengan tuduhan berzina), mereka dilaknat di dunia dan di akhirat, dan mereka akan medapatkan azab yang besar (23). Yaitu pada hari (ketika) lidah, tangan, dan kaki mereka menjadi saksi atas mereka terhadap apa yang dahulu mereka kerjakan (24).12

\section{Analisis Sosial Hukum Islam Qs An-Nur Ayat 22}

Hukum yang terdapat dalam Al-Qur'an berhubungan erat dengan realitas masyarakat. Relasi antara nas dengan realitas dapat berfungsi sebagai tool of social engineering dan tool of social control. Fungsi tool of social engineering bertujuan agar nas hukum mampu mengubah perilaku sosial masyarakat ke arah yang lebih baik, sedangkan fungsi tool of social control adalah agar hukum yang berlaku dapat mengendalikan dan mengawasi perilaku sosial tersebut. ${ }^{13}$

Kedua fungsi hukum tersebut dapat dilihat pada latar belakang turunnya surah An-Nur ayat 22. Ayat ini mengajarkan nilai-nilai pemaafan dan kasih sayang antar sesama manusia baik dalam hubungan kekerabatan maupun hubungan di luar kekerabatan. Pada ayat ini, prinsip sosial digandengkan dengan kualitas ketaatan kepada Allah. Hal ini tercermin pada narasi larangan memutuskan kerjasama dengan kerabat dan orang lain dan kalimat hendaklah mereka memaafkan dan berlapang dada serta kalimat apakah kamu tidak suka Allah mengampunimu?

Narasi pertama yaitu hendaklah mereka memaafkan dan berlapang dada berfungsi sebagai tool of social engineering sehingga di sini hukum bermaksud untuk mengubah rasa permusuhan menjadi kasih sayang, rasa sakit hati karena dikhianati oleh kerabat menjadi kebesaran jiwa untuk memaafkan. Ayat ini menyiratkan penerapan nilai etika sosial yang luhur bahwa berbuat baik ketika orang membalasnya dengan kebaikan adalah kondisi yang wajar, namun berbuat baik meski orang tersebut membalasnya dengan keburukan adalah kondisi yang luar biasa.

Pada saat fitnah tentang putrinya tersebar, Abu Bakar mengalami sebuah gejolak emosional sekaligus tekanan sosial dari kaumnya. Kondisi ini semakin memuncak tatkala ia mengetahui bahwa anak bibinya adalah salah satu dari para pelaku fitnah sehingga menyebabkan sisi emosionalnya memutuskannya untuk bertindak. Secara sosiologis, manusia yang berperan sebagai partisipan aktif dalam pembangunan realitas sosial seringkali menemui situasi yang tidak dapat diprediksi. Hal yang tidak menentu telah terjadi, sementara partisipan harus membangun sebuah rasa tentang apa yang terjadi dan bagaimana harus bertindak sehingga mengabaikan pertimbangan secara sadar dan mendalam. Sebaliknya, partisipan meresponnya dengan cara-cara praktis dan tidak reflektif agar ia dapat melegetimasi tindakan yang dilakukan sebagai

12 Kementrian Agama RI, Terjemah QS An-Nur ayat 23-24 dalam Qur'an Kemenag Versi 1.3.3.9 (Aplikasi Mobile Android), Lajnah Pentashihan Mushaf Al-Qur'an, 2018.

13 Muhammad Mufid, "Aplikasi Fiqh al-Wa>qi': Pertimbangan-Pertimbangan Aspek Sosiologis dalam Pemikiran al-Qarad\}a>wi>," Istinbath Vol. 14 no. 2 (2017): h. 274. http://ejournal.metrouniv.ac.id/index.php/istinbath/article/view/798/788. (1 April 2019). 
respon atas pengalaman di sekitarnya. ${ }^{14}$

Ditinjau dari teks dan konteks sabab nuzul ayat ini, maka dapat ditemukan potret kehidupan sosial yang terjadi pada saat aturan hukum tersebut ditetapkan. Abu Bakar merupakan salah satu pemuka agama dalam masyarakatnya sekaligus berposisi sebagai mertua Rasulullah juga dapat terpengaruh oleh gejolak sosial. Bahkan Aisyah, wanita yang dipilih oleh Allah untuk mendampingi Rasulullah sebagai istrinya sekaligus dijuluki sebagai Ummul Mukminin juga tidak sepi dari isu negatif yang dilontarkan oleh masyarakatnya. Di sini dapat dilihat bahwa gejolak dan konflik sosial yang berujung pada tindakan-tindakan non reflektif dapat terjadi pada siapa saja, terlepas dari status sosialnya. Budaya bergosip, fitnah, menyebarkan berita bohong masih juga ditemukan hingga masyarakat dewasa ini, terutama dengan pesatnya kemajuan teknologi internet. Peristiwa fitnah zaman sekarang populer dengan istilah hoax.

Oleh karena itu, syariat menetapkan sanksi yang tegas bagi pelaku dan penyebar fitnah. Para ulama sepakat bahwa al-qadzif atau orang yang menuduh orang lain berzina, jika tidak dapat mendatangkan empat orang saksi atas kebenaran tuduhannya dan tidak bertaubat maka ia wajib mendapatkan 3 jenis hukuman: pertama, didera 80 kali; kedua, tidak diterima persaksiannya; ketiga, jika ia tidak bertaubat maka dia dihukumi sebagai orang fasik. Para ulama juga sepakat jika si penuduh tersebut bertaubat, ia tetap wajib dihukum dera 80 kali. $^{15}$

Dari segi hukum taubatnya, Imam Malik, Syafi'i, dan Ahmad berpendapat bahwa jika al-qadzif bertaubat maka persaksiannya boleh diterima dan statusnya sebagai orang fasik terhapuskan. Mereka berhujjah dengan apa yang dilakukan oleh Khalifah Umar terhadap Abu Bakrah. Mazhab Imam Abu Hanifah al-Auza'i, dan lainnya berpendapat bahwa status kefasikan dan tidak diterima persaksiannya berlaku selama-selamanya meski ia sudah bertaubat. Pendapat terkuat adalah pendapat mazhab pertama. ${ }^{16}$

Ketika seorang individu membuat kesimpulan-kesimpulan yang berujung pada tindakan-tindakan yang keluar dari batasan, maka di sinilah hukum menjadi tool of social control. Semua tindakan masyarakat diatur dan diorganisasi oleh aturan, tetapi aturan tersebut hendaklan tertanam sebagai sebuah prinsip yang kuat sehingga tumbuh sebagai keniscayaan atau kebiasaan yang nantinya menjelma menjadi bagian dari kebudayaan positif dalam masyarakat. ${ }^{17}$

Al-Qur'an sebagai kaidah hukum melakukan berbagai macam pendekatan untuk mewujudkan fungsi tool of social control tersebut, sebagaimana teori Hans Kelsen (1961) yang mengemukakan bahwa salah satu pendekatan kontrol sosial tersebut adalah

\footnotetext{
14 John Scott, Social Theory: Central Isuues in Sociology, terj. Ahmad Lintang Lazuardi, Teori Sosial Masalah-Masalah Pokok dalam Sosiologi (Cet. I; Yogyakarta: Pustaka Pelajar, 2012), h. 183.

15 'Abdul Fattah 'Asyur, Manhaj al-Qur'a>n fi> Tarbiyah al-Mujtama' (Cet. I; Mesir: Maktabah alKhanji, 1979), h. 135.

${ }^{16}$ Abdul Fattah 'Asyur, Manhaj al-Qur'a>n fi> Tarbiyah al-Mujtama', h. 137-138.

17 John Scott, Social Theory: Central Isuues in Sociology, h. 183.
} 
dengan melakukan imbalan-imbalan psikologis bagi pemegang peranan yang patuh maupun melanggar kaidah-kaidah hukum sekaligus mengusahakan perubahan persepsi, nilai, dan sikap para pemegang peranan. ${ }^{18}$ Pada ayat 22 surah An-Nur tersebut, imbalan yang bersifat psikologis sekaligus berorientasi spiritual untuk hamba yang mau memaafkan saudaranya yaitu mendapatkan pengampunan dari Allah.

Pada ayat ini pula terdapat beberapa prinsip yang diharapkan menjadi kaidah hukum berinteraksi antarindividu, yaitu:

1. Islam melarang manusia untuk bersumpah dalam hal yang buruk

2. Islam melarang manusia memutuskan kerjasama sosial dengan orang lain, terutama kerabat dan orang-orang yang membutuhkan.

3. Islam mengajarkan manusia untuk berbuat baik dengan ikhlas tanpa bergantung pada bentuk balasan yang diterimanya.

4. Islam mengajarkan manusia untuk mengendalikan sikap egoisme dan emosionalnya melalui perintah berlapang dada dan memaafkan kesalahan orang lain.

5. Islam mengingatkan manusia bahwa sikap memaafkan tersebut adalah bagian dari implementasi keimanan dan ketaatannya kepada Allah.

Kaidah-kaidah interaksi tersebut bukan hanya berdampak positif bagi budaya subjeknya, tetapi juga objek yang dituju terutama tiga golongan muslim yang disebutkan dalam ayat 22 surah an-Nur:

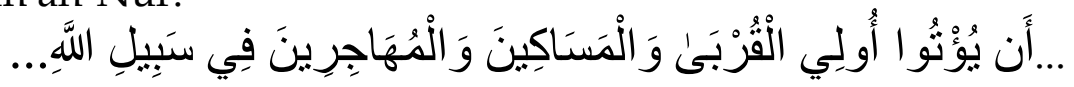

Penyebutan tiga golongan ini yaitu kerabat, orang-orang miskin, dan muhajirin juga memberikan potret sosial masyarakat ketika itu. Pada periode penyebaran dakwah Islam di Madinah, Rasulullah juga melakukan proses keadilan ekonomi dalam semua lapisan masyarakat. Tiga kelompok inilah yang mengalami kesulitan finansial sehingga dijadikan sebagai prioritas untuk menerima santunan dari sesama muslim. Hal ini sekaligus menunjukkan bahwa relasi sosial yang kuat tidak dapat dipisahkan dari pembangunan perekonomian.

\section{KESIMPULAN}

Sebuah teks hukum senantiasa tidak terlepas dari konteks yang melatarbelakanginya, baik itu dari segi historis maupun sosial. Kajian tentang konteks dari ayat hukum pada QS An-Nur ayat 22 menunjukkan bahwa al-Qur'an tidak mengabaikan realitas sosial masyarakat yang menerima wahyu tersebut. Di sisi lain, adanya nilai-nilai sosial pada nas hukum juga dapat menjadi cerminan dan bukti historis tentang bagaimana perkembangan dan problematika masyarakat di era turunnya wahyu. Oleh karena itu, hukum yang terkandung dalam nas bukan hanya berfungsi sebagai pedoman keagamaan atau tuntunan spritual, tetapi juga sebagai

18 Hans Kelsen dalam Soerjono Soekanto, Pokok-Pokok Sosiologi Hukum (Cet. XXIV; Jakarta: Rajagrafindo Persada, 2016), h. 142. 
pedoman sosial sekaligus kontrol hukum yang dapat diterapkan seiring dinamika zaman.

\section{DAFTAR PUSTAKA}

Afandi, Irfan. "Hoax dalam Sejarah Islam Awal (Kajian Kritis tentang QS An-Nr: 11-20)". ArRisalah Vol. XVI No. 1 (2018), h. 161.

Ali al-Syaikh, Shalih bin 'Abdul 'Aziz. al-Tafsi>r al-Muyassar. Madi>nah: Maktabah al-Malik al-Fahd, $1420 \mathrm{H}$.

Ali, Zainuddin. Sosiologi Hukum. Jakarta: Sinar Grafika, 2015.

Amin, Ma'ruf. Fatwa dalam Sistem Hukum Islam. Cet.I: Jakarta: elSAS, 2008.

Al-'Asqalani, Ibnu Hajar. Fath\} al-Ba>ri> bi Syarh al-Bukha>ri>. Juz 10. Cet. I; Riyad: Dar alTaibah, 2005.

'Asyur, Abdul Fattah. Manhaj al-Qur'a>n fi> Tarbiyah al-Mujtama'. (Cet. I; Mesir: Maktabah al-K>hanji, 1979.

Kementrian Agama RI. Qur'an Kemenag Versi 1.3.3.9 (Aplikasi Mobile Android). Lajnah Pentashihan Mushaf Al-Qur'an, 2018.

Mufid, Muhammad. "Aplikasi Fiqh al-Wa>qi': Pertimbangan-Pertimbangan Aspek Sosiologis dalam Pemikiran al-Qarad \}a>wi>”. Istinbath Vol. 14 no. 2 (2017): h. 273-295 http://ejournal.metrouniv.ac.id/index.php/istinbath/article/view/798/788. (1 April 2019).

Riyani, Irma. "Menelusuri Latar Historis Turunnya al-Qur'an dan Proses Pembentukan Tatanan Masyarakat Islam". Al-Bayan vol. 1 No. 1 (Juni 2916), h. 27-33.

Rofiq, Ahmad. Fiqh Kontekstual dari Normatif ke Pemaknaan Sosial. Cet. II; Yogyakarta: Pustaka Pelajar, 2012.

Al-Sabuni, Muh\}ammad 'Ali. Rawa 'i al-Baya $>n$ Tafsi $>r$ A $\langle\langle y a>t$ al-Ah $\} a r>m$ min alQur' $a>n$. Juz 2. Cet. I; Jakarta: Dar al-Kutub al-Isla>miyyah, 2001.

Scott, John. Social Theory: Central Isuues in Sociology. Terj. Ahmad Lintang Lazuardi. Teori Sosial Masalah-Masalah Pokok dalam Sosiologi. Cet. I; Yogyakarta: Pustaka Pelajar, 2012.

Soekanto, Soerjono. Pokok-Pokok Sosiologi Hukum. Cet. XXIV; Jakarta: Rajagrafindo Persada, 2016.

Al-Suyuthi, Jalaluddin. Asba>b al-Nuzu>l. Cet. I; Beirut: Mu'assah al-Kutub al-Saqafiyyah, 2002.

Tadmuri, 'Umar 'Abdussalam (ed.). al-Sirah al-Nabawiyyah li Ibni Hisya >m. Juz 3 Beirut: Dar al-Kitab al'Arabi, 1990. 